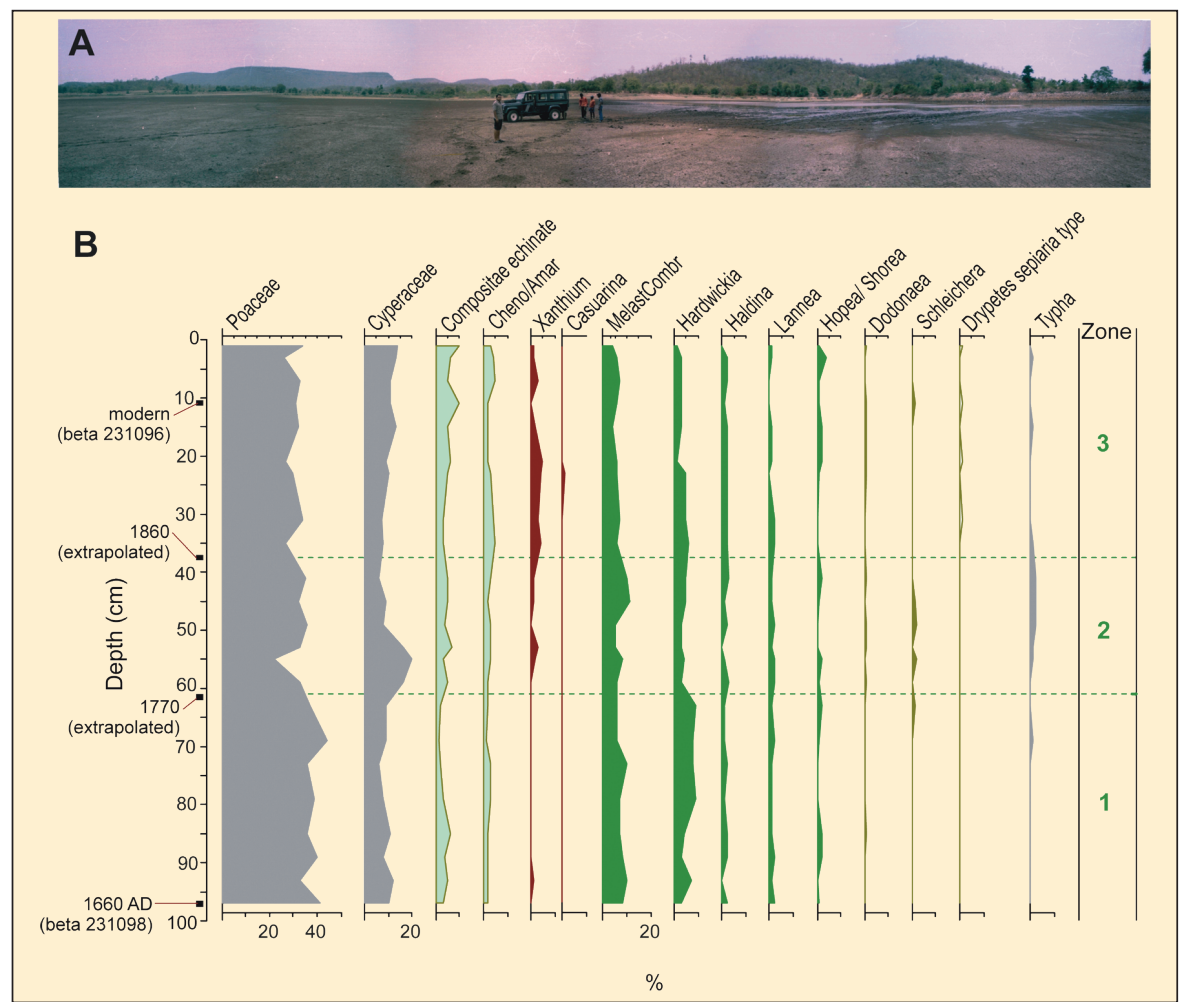

Figure 1: Although there are very few natural lakes in peninsular India, there is an abundance of water reservoirs with artificial levees commonly referred to as "tanks", dotting the landscape of south India (Gunnell and Anupama, 2003). Several thousand tanks cover the south Indian landscape and offer the best potential for pollen-vegetation modeling in this region, of which Potapuram cheruvu $(\boldsymbol{A})$ is an example. A late Holocene pollen diagram from a core in this tank (B; Anupama et al., 2008) illustrates human impact on the landscape (red) as interpreted from markers such as Xanthium (a weed) and Casuarina (common plantation tree) and other plantation trees occurring in tandem but in small proportions (Eucalyptus, Cocos, Tamarindus and Tectona). Significant among the deciduous forest catchment's markers (dark green) are Melastomataceae/Combretaceae, Haldina, Hardwickia, and Lannea.

with a presentation on the first quantitative pollen-inferred Holocene land-cover in northwest Europe achieved within the Swedish LANDCLIM project (Gaillard et al., 2010). Lectures on the second day included an introduction to dynamic vegetation models, tools for spatial analyses, and studies in other regions (tropical Africa and Australasia). The third day comprised of invited talks on the dry evergreen forests of southern India and on the online Historical Atlas of south India (http://www.ifpindia. org/hatlas/). Palynological and multiple proxy studies in southern India, Sri Lanka and Borneo were presented during several lecture and poster sessions (Fig. 1).
As a concrete result of the workshop, three geographical regions of focus on the Indian subcontinent and their respective regional coordinators were identified, (1) Western Himalayas, (2) Eastern Himalayas, and (3) Peninsular India with Sri Lanka. These regions will each move forward in developing the following research themes (with their respective thematic coordinators):

A) Indian pollen database (to be housed at the IFP) and application of the biomization approach.

B) Pollen productivity estimates and landscape reconstruction algorithm application.
C) Archeology and paleoecology (syntheses and databases). Given the diversity of Indian archeology, an investigation into the long-term trends in the environmental context of human adaptation is essential. Starting with collecting all available, environmental proxies from archeological and historical contexts, the plan is to select sites/areas to carry out new case studies with standardized methods to answer specific questions through the establishment of multi-disciplinary research groups.

For the names of regional and thematic coordinators, please see the supplementary material (http://www.pages-igbp.org/ products/newsletters/ref2011_2.pdf) or contact the first author of this report. The research stemming from the above mentioned aims will contribute to the PAGES Focus 4 PHAROS themes of Regional Integration and Land-cover and Use.

A post-workshop excursion to a 30 year afforestation effort of the Sri Aurobindo International Centre of Education, aptly illustrated land-cover changes and positive aspects of human intervention through restoration ecology.

\section{References}

Gaillard, M.-J., et al., 2010: Holocene land-cover reconstructions for studies on land cover climate feedbacks, Climate of the Past, 6 : 483-499.

Sugita, S., 2007a: Theory of quantitative reconstruction of vegetation. I. Pollen from large sites REVEALS regional vegetation, The Holocene, 17: 229-241.

Sugita, S., 2007b: Theory of quantitative reconstruction of vegetation II: all you need is LOVE, The Holocene, 17: 243-257.

Anupama, K., Sudhakar, S., Prasad, S. and Pujar, G.S., 2008: Temporal dynamics using a spatially resolved technology: applying RS to target sites for reconstructing vegetation history in the Eastern Ghats, Proceedings of the National Seminar on Conservation of the Eastern Ghats, December 28-29, 2007, ENVIS Centre, Hyderabad, 474-477.

Gunnell, Y. and Anupama, K., 2003: Past and Present Status of Runoff Harvesting Systems in Dryland Peninsular India: A Critical Review, Ambio, 32(4): 320-324.

For full references please consult:

http://www.pages-igbp.org/products/newsletters/ref2011_2.pdf

\title{
2010 international workshop on XRF core scanning
}

\section{Texel, The Netherlands, 8-10 September 2010}

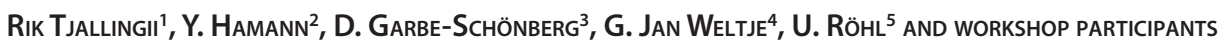

${ }^{1} \mathrm{NIOZ}$-Royal Netherlands Institute for Sea Research, Texel, The Netherlands; Rik.Tjallingii@nioz.nl

${ }^{2}$ Geological Institute, ETH, Zürich, Switzerland; ${ }^{3}$ nnstitute of Geosciences, CAU University of Kiel, Germany; ${ }^{4}$ Department of Geotechnology, Delft University of Technology, The Netherlands; ${ }^{M}$ MARUM-Center for Marine Environmental Sciences, University of Bremen, Germany

Over the last decade, X-ray fluorescence (XRF) core scanning has become an established method for non-destructive and fast acquisition of sediment compositions (i.e., element count rates) directly at the surface of split cores. State-of-the-art core scanners can measure element intensities at sub-millimeter resolution that allow detailed recording of compositional variations in finely laminated and even varved sediments. Core-scanning data are widely applied to paleoceanographic and pa- leoclimate reconstructions on timescales ranging from seasonal to millions of years. New developments in data processing and calibration techniques have increased the need to exchange experiences among users at various laboratories equipped 
A) X-PIPS detector

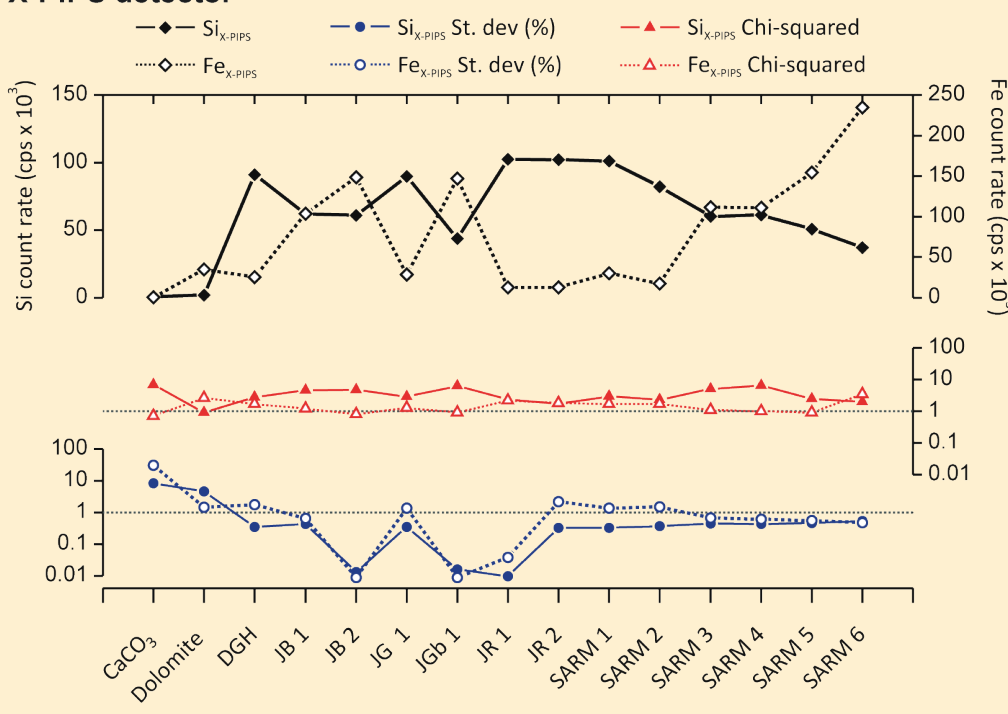

B) SDD detector

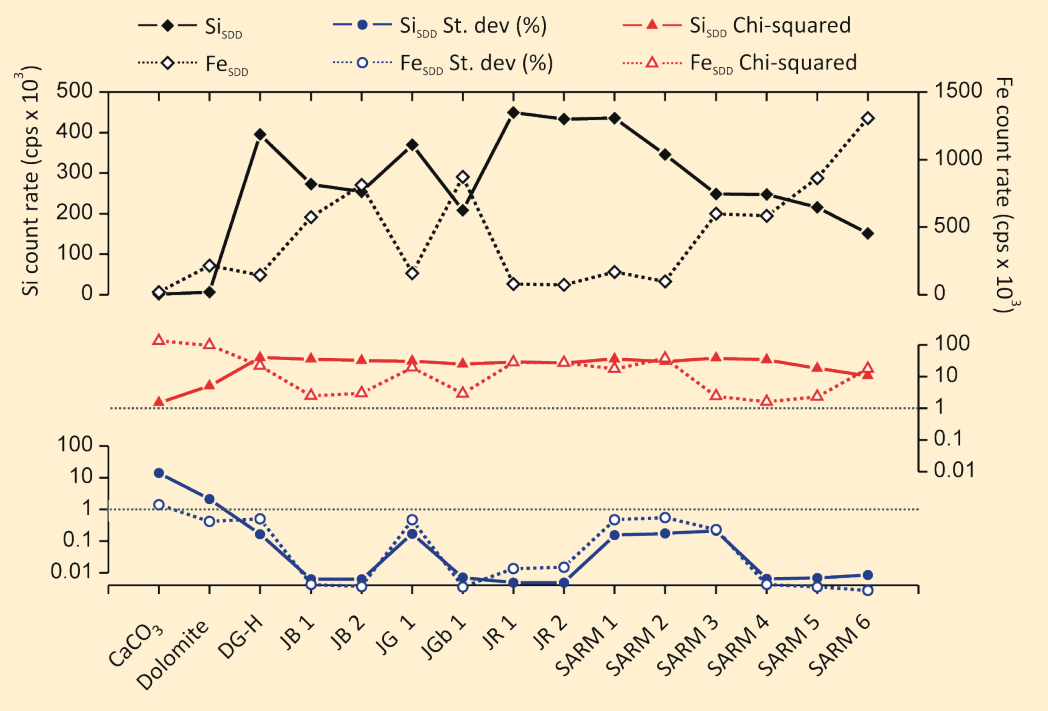

Figure 1: Comparing count rates and goodness-of-fit statistics of element silicon (Si) and iron (Fe) measured on certified geochemical reference standards (X-axis; e.g., http://georem.mpch-mainz.gwdg.de/) with an Avaatech core scanner equipped with $\boldsymbol{A}$ ) a pin-diode detector (X-PIPS) and $\boldsymbol{B}$ ) a silicon-drift detector (SDD). The newly developed SDD detector increases the count rate (black) but also chi-square statistics (red) for Si and Fe due to higher sensitivity of this detector. The relative standard deviation (blue) decreases indicating better signal-to-noise conditions for measurements acquired with the SDD detector. The relative standard deviation is calculated as D-Area/ElementArea. For practical reasons the chi-square and relative standard deviation are plotted on a logarithmic scale.

with an XRF core-scanner. Therefore, a three-day workshop was held at the Royal Netherlands Institute for Sea Research to discuss technical aspects and application challenges of XRF core scanning, in particular Avaatech scanners, in the wider field of paleoceanography.

On the first day of the workshop, leading researchers and laboratories gave an overview on applications of geochemistry to scientific problems and on the quality of geochemical data generated by XRF core scanning. The quality of XRF corescanner data is commonly evaluated by comparing core-scanner records with destructive analyses of discrete samples (e.g., Inductively Coupled Plasma (ICP)-Optical Emission Spectroscopy or ICP-Mass Spectroscopy). Geochemical data are closedsum data that are intrinsically correlated by means of appropriate multivariate filtering techniques. Log-ratio calibration permits rigorous quantification of the precision of XRF core-scanner data based on replicate measurements, which paves the way to fully quantitative applications of XRF core scanning.

The second day was dedicated to the discussion of the mathematical transformation of XRF spectra into elemental count rates by least-squares fitting of the characteristic X-ray peaks. Practical problems concerning data processing and goodness-of-fit parameters (e.g., chisquared $X^{2}$ ) were presented by members of the MARUM XRF core scanner laboratory of the University of Bremen, Germany. Many technical issues were discussed in a lively debate between XRF core-scanner users, specialists in XRF acquisition, and specialists in XRF spectrum evaluation. One of the key points in this discussion was that the increased efficiency of recently developed digital XRF detectors significantly reduces measurement times and increases the signal-to-noise ratio. However, this increased sensitivity of digital detectors also brings out the complexity of XRF spectra, which may result in strongly increased c2 statistics suggesting a poor spectrum fit. A suitable alternative approach to the use of $\mathrm{c} 2$ statistics is to express the goodness-of-fit in terms of relative errors (i.e., the standard deviation as a proportion of the element intensity; Fig. 1). As a rule of thumb, elements displaying negative count rates or relative errors in excess of $10 \%$ are considered to be below the detection limit.

The third day was devoted to complementary non-destructive scanning tools, which are optional for the latest scanners (e.g., visible-light and UV digital line-scan cameras, magnetic susceptibility sensors, radiograph imagery), and their applications to sediment and coral-core analysis. In addition, laser-ablation ICP-spectroscopy was presented as a complementary destructive chemical technique. In a final discussion, the workshop participants expressed the need for an electronic information platform to share practical experience on sample preparation, measurement techniques, data processing, technical solutions and preventive maintenance.

The next international workshop on XRF sediment core scanning will be held in two years time. More information about current developments concerning the electronic information platform and the workshop, including some of the presentations, is available at: www.nioz.nl/xrfworkshop and cannot be directly quantified on an core composition variations in terms of changes in climate and environment, sediment transport mechanisms, or diafrom XRF scanners are but are also affected by down-core varia tions of physical sediment properties (size distribution, density, water content), as well as absorption and enhancement effects, and measurement geometry. It was shown that the log-ratio representation of XRF count rates and concentrations allows effective minimization of the noise caused by these down-core variations, and allows enhancement of the signal-to-noise ratio 